University of Nebraska - Lincoln

DigitalCommons@University of Nebraska - Lincoln

January 1988

\title{
Versatile new metalorganic process for preparing superconducting thin films
}

M.E. Gross

AT\&T Bell Laboratories, Murray Hill, New Jersey

M. Hong

AT\&T Bell Laboratories, Murray Hill, New Jersey

Sy_Hwang Liou

University of Nebraska-Lincoln, sliou@unl.edu

P.K. Gallagher

AT\&T Bell Laboratories, Murray Hill, New Jersey

J. Kwo

AT\&T Bell Laboratories, Murray Hill, New Jersey

Follow this and additional works at: https://digitalcommons.unl.edu/physicsliou

Part of the Physics Commons

Gross, M.E.; Hong, M.; Liou, Sy_Hwang; Gallagher, P.K.; and Kwo, J., "Versatile new metalorganic process for preparing superconducting thin films" (1988). Si-Hwang Liou Publications. 23.

https://digitalcommons.unl.edu/physicsliou/23

This Article is brought to you for free and open access by the Research Papers in Physics and Astronomy at DigitalCommons@University of Nebraska - Lincoln. It has been accepted for inclusion in Si-Hwang Liou Publications by an authorized administrator of DigitalCommons@University of Nebraska - Lincoln. 


\title{
Versatile new metalorganic process for preparing superconducting thin fllms
}

\author{
M. E. Gross, M. Hong, S. H. Liou, P. K. Gallagher, and J. Kwo
}

AT\&T Bell Laboratories, Murray Kill, New Jersey 07974

(Received 27 October 1987; accepted for publication 20 November 1987)

A new technique for producing thin films of the high-temperature perovskite superconductors, Ln $\mathrm{Ba}_{2} \mathrm{Cu}_{3} \mathrm{O}_{7-x}$, where $\mathrm{Ln}$ represents a rare-earth element, using spin-on metalorganic precursors is described. Pyrolysis of the spin-coated films, consisting of mixed metal (2-ethyl hexanoates), leads to black fins up to several microns thick whose degree of orientation is a function of the processing temperature and duration. Representative fims of $\mathrm{YBa}_{2} \mathrm{Cu}_{3} \mathrm{O}_{7} \cdot x$ on MgO begin to exhibit orientation with the $c$ axis perpendicular to the Amm plane at heat treatments above $900^{\circ} \mathrm{C}$. The superconducting behavior of a highly oriented film produced at $990^{\circ} \mathrm{C}$ is characterized by $T_{c}$ (onser) $=89 \mathrm{~K}, T_{c}(R=0)=77 \mathrm{~K}$, and $J_{c}=10^{3} \mathrm{Am}^{-2}$ at 65 K.

The recent discovery of materials that exhibit superconductivity at $90 \mathrm{~K}^{1}$ has generated much interest in developing their technological applications. These cuprate superconductors, of composition $\mathrm{LnBa}_{2} \mathrm{Cu}_{3} \mathrm{O}_{7} \ldots{ }_{2}{ }^{2}$ where $\mathrm{Ln}$ is a Fare-earth element, have now been prepared by a variety of physical and inorganic chemical techniques. The standard route to preparation of bulk materials involves mixing the elements as the oxides, carbonates, nitrates, oxalates, etc. followed by sintering at elevated temperatures. ${ }^{3}$ Thorough mixing of the components to produce a homogeneous mixture remains a problem with the solid-state route. Thus, repeated milling and sintering cycles are needed to achieve the proper phase. Thin slms, on the other hand, have required more sophisticated techniques. Superconducting thin fims have been produced by e-beam evaporation, ${ }^{4}$ sputtering, molecular beam epitaxy, ${ }^{6}$ and laser desorption. ${ }^{7}$

Our interest lles in developing new methods for bulk and thin-film preparation using homogeneous solution techniques. Mixing at the molecular level should improve formation of the desired material and crystallographic phase. The strategy we are pursuing involves synthesis of metalorganic precursors for the elements of interest. Solutions of the combined precursors are spin coated and fired to produce superconducting films from a few thousand angstrons to several microns thick. Altematively the homogeneous solution can be evaporated and the resulting solid pyrolyzed to give powders of the superconductor.

Copper bis(2-ethyl hexanoate) $\left[\mathrm{Cu}\left(\mathrm{C}_{4} \mathrm{H}_{9} \mathrm{CH}\left(\mathrm{C}_{2} \mathrm{H}_{5}\right) \mathrm{CO}_{2}\right)_{2}\right]$ bariurs bis(2-ethy! hexanoate) $\left[\mathrm{Ba}\left(\mathrm{C}_{4} \mathrm{H}_{9} \mathrm{CH}\left(\mathrm{C}_{2} 3 \mathrm{H}_{5}\right) \mathrm{CO}_{2}\right)_{2}\right]$, and yttrum tris (2-ethyl hexanoate) $\left[\mathrm{Y}^{\prime}\left(\mathrm{C}_{4} \mathrm{H}_{9} \mathrm{CH}\left(\mathrm{C}_{2} \mathrm{H}_{5}\left(\mathrm{CO}_{2}\right)_{3}\right]\right.\right.$ were prepared by published methods. ${ }^{8}$ As it is common for metal carboxylates to retain solvent of crystallization in their coordination sphere, the metal content of the precursors was determined by thermogravimetry (TG) in $\mathrm{O}_{2}$ using a Perkin-Elmer thermal analysis system 7 . The carboxylate precursors were dissolved in chloroform in the ratio $1 \mathrm{Y}: 2 \mathrm{Ba} 3 \mathrm{Cu}$ to give homogeneous solutions, whose viscosity was adjusted by varying the concentration. A typical sample prepared using the mixed carboxylates solution (1 $\mathrm{M}[\mathrm{Cu}]$ ) at a spin speed of 2000 rpm gave a final fim thickness of $\sim 1.4 \mu \mathrm{m}$. Films were pyrolyzed in a programmable tube furnace under a steady flow of $\mathrm{O}_{2}$. Film thicknesses were calculated on the basis of weight gain using a density for the superconduetor of $6.3 \mathrm{~g} \mathrm{~cm}^{-3}$.

The selection of precursors for the metalorganic route to superconductors was based on the following desired properthes: (1) complexes of the different elements should be mutually compatible; (2) precursors should be soluble in a solvent suitable for spin coating; (3) precursor solutions should form homogeneous, continuous flms; (4) precursors should decompose cleanly, i.e., leave no resicual carbon. Our previous experience with palladium acetate ${ }^{9}$ led us to look at carboxylate complexes of $\mathrm{Cu}, \mathrm{Ba}$, and the rare earths. In these complexes, the two $O$ atoms of each carboxylate are bonded directly to the metal and the organic substituent has a direct effect on the solubility. A long hydrocarbon chain improves the solubility of the complex in organic solvents. The carboxylate that we chose for our initial studies, 2-ethyl hexanoate (abbreviated 2-EH), is shown in Fig. 1. The $\mathrm{Cu}^{2+}, \mathrm{Ba}^{2+}$, and $\mathrm{Ln}^{3+}$ complexes contain, respectively, 2, 2, and 3 molecules of 2-EH. TG of these complexes in $\mathrm{O}_{2}$ shows that complete decomposition to the respective oxides, $\mathrm{CuO}$, $\mathrm{BaO}$, and $\mathrm{Y}_{2} \mathrm{O}_{3}$, occurs at 300,379 , and $322^{\circ} \mathrm{C}$. Chloroform solutions of the complexes are prepared in the molar ratio 1 Y:2 Ba:3 Cu. The use of these homogeneous solutions favors uniform formation of the superconducting material.

A typical sample is prepared by spin coating a substrate such as $\mathrm{ZrO}_{2}$ or $\mathrm{MgO}$ at $2000 \mathrm{rpm}$ or dipping the substrate in the solution and drying horizontally. $\mathrm{MgO}$ and $\mathrm{ZrO}_{2}$ substrates were used in these preliminary studies to prevent harmful interaction with the ternary ceramic material. Prebaking at $100^{\circ} \mathrm{C}$ removes the residual solvent. Samples are then fired in a steady stream of $\mathrm{O}_{2}$ to a maximum temperature of $800-990^{\circ} \mathrm{C}$ followed by annealing at $400^{\circ} \mathrm{C}$. The $\mathrm{TG}$ results suggest that complete pyrolysis of the films and removal of organic components occur by $400^{\circ} \mathrm{C}$. Continuation of the processing to higher temperatures achieves solid-state reaction of the materials and increasing grain growth. The $x$ ray diffraction patterns of films fired at different naximum

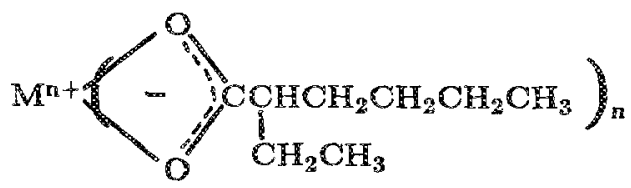

FIG. 2. Representative structure of a metal 2-ethyl hexanoate complex. 
temperatures and annealed at $400^{\circ} \mathrm{C}$ are shown in Fig. 2 . Notice the increasing degree of $c$-axis orientation perpendicular to the fim plane with increasing process temperatures. The high-temperature step in the processing is extremely short, 3 min at the maximum. Despite the high ternperature needed to achieve orientation, the short processing times may preciude significant interaction of the film with the substrate. Scanning electron mircrographs of these same films are shown in Fig. 3. The sample prepared at $990^{\circ} \mathrm{C}$ contains platelets of material (Fig. 4) that must be related to the high degree of $c$-axis oreintation seen in the $k$-ray diffraction pattern [Fig. 2(a)]. At lower temperatures we find the smaller grain size associated with more random crystallographic orientations.

The superconducting characteristics of these films are extremely promising for further development and applications. Figure 5 shows a plot of resistivity versus temperature for the film processed at $990^{\circ} \mathrm{C}$. Note the metallic behavior of the film above the superconducting transition temperature. The onset of the superconducting transition occurs at $89 \mathrm{~K}, T_{\mathrm{c}}(R=0)=77 \mathrm{~K}$, and $J_{c}$, measured at $65 \mathrm{~K}$, is about $10^{3} \mathrm{~A} \mathrm{~cm}^{-2}$. We are in the process of analyzing our films to determine the level of contamination that might be present. Our To results lead us to believe that C contamination in these films should be minimal.

During the preparation of this manuscript we became aware of related work using metal acetates ${ }^{10}$ and naphthenates. "The former method suffers from the limited solubilities of the metal acetates, such that hot aqueous acetic acid solutions of the acetates must be used in order in spin coat a homogeneous film. This solubility problem often leads to precipitation of the metal complexes during the rapid cooling of the spin-coating process, producing an inhomogeneous fim. It aiso places severe limits on the achievable fim thickness. The 2-EH precursors that we use are more soluble

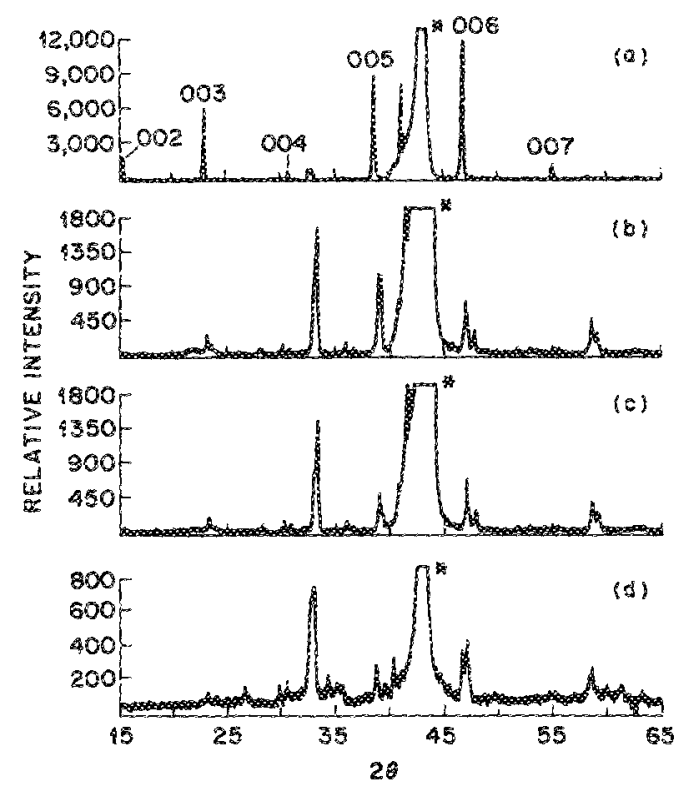

FlG. 2. X-ray diffraction pattern of a $\sim 1.4 \mu \mathrm{m} \quad \mathrm{YBa} \alpha_{2} \mathrm{Cu}_{3} \mathrm{O}_{7-x}$ film formed by pyrolysis at (a) $990^{\circ} \mathrm{C}$, (b) $950^{\circ} \mathrm{C}$. (c) $900^{\circ} \mathrm{C}$. and (d) $825^{\circ} \mathrm{C}$. Diffraction lines of the Mgo substrate are indicated by *.
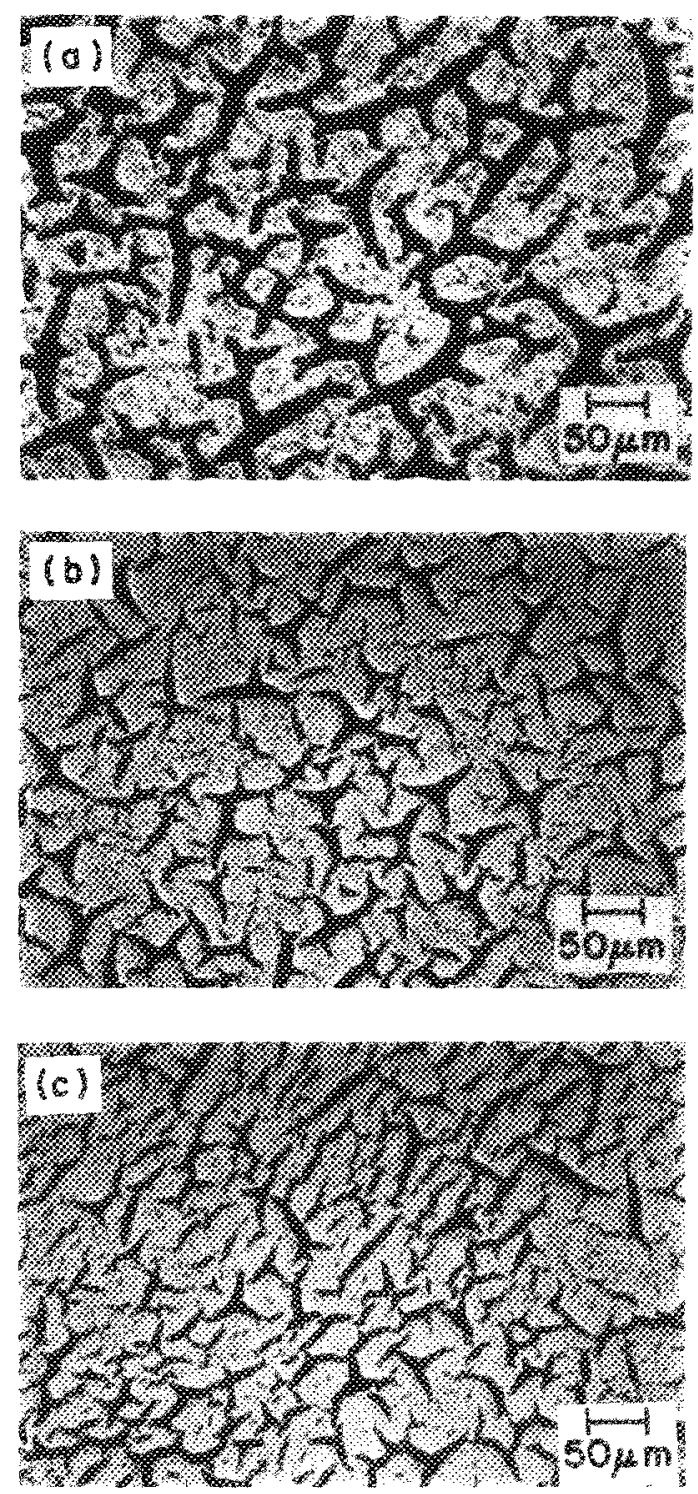

FYG. 3. Scanning clectron micrograph of $a-1.4 \mu \mathrm{m} \mathrm{YBaCu} \mathrm{O}_{7}$ formed by pyrolysis at (a) $9900^{\circ} \mathrm{C}$, (b) $950^{\circ} \mathrm{C}$, and (c) $900^{\circ} \mathrm{C}$. White areas correspond to the superconducting material. Dark areas are the MgO substrake.

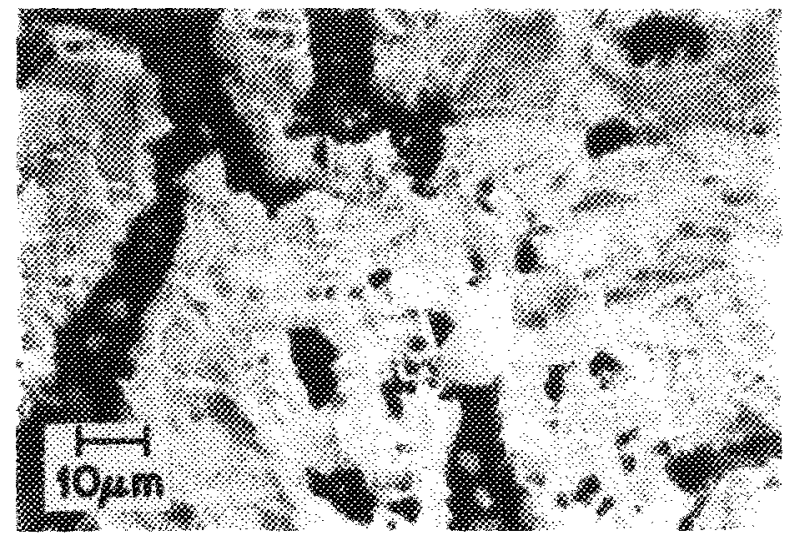

FIG. 4. Scanning electron microgrpah at higher magnification of a $990^{\circ} \mathrm{C}$ film shown in Fig. 3(a). 


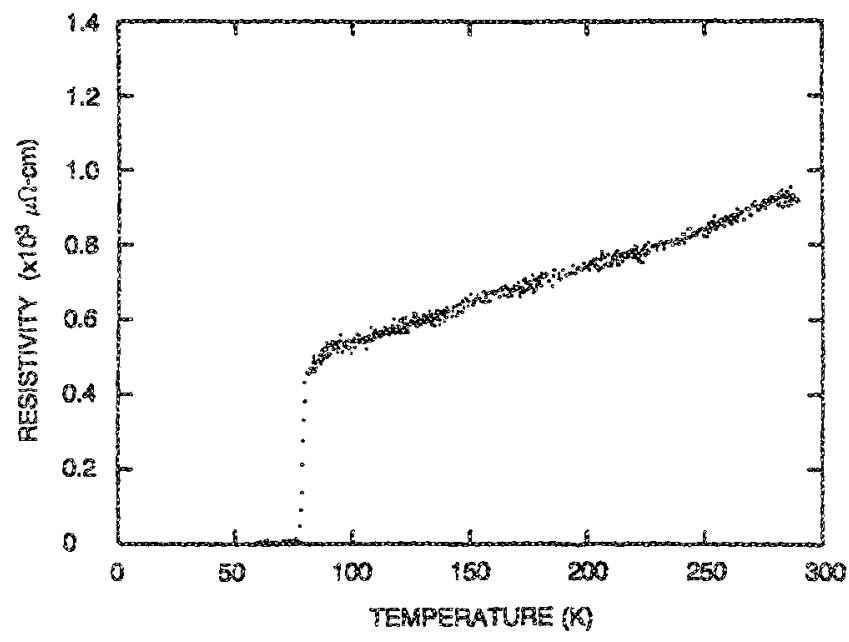

EK. 5. Rasistivity vs temperature for a $\sim 1.4 \mu \mathrm{mBa} \mathrm{YB}_{2} \mathrm{Cu}_{7}$. fim.

than the acetates, allowing us a much greater flexibility in choice of $\mathrm{fl}$ thickness. The electrical characteristics of our fins are also superior to those reported for the acetate process. We have produced films of $\mathrm{ErBa}_{2} \mathrm{Cu}_{3} \mathrm{O}_{7 . . x}$ from spincoated acetate solutions to compare processes. These Er flims exhibit much improved electrical characteristics $\left[T_{c}\right.$ (onset) $\left.=80 \mathrm{~K} ; T_{c}(R=0)=66 \mathrm{~K}\right]$ over the reported $Y$ acetate work, but we are not optimistic about the utility of this process in light of our success with the 2-EH complexes. Results of the Er work will be discussed elsewhere. ${ }^{12}$

The reported metal naphthenate process involves formation of $1-3 / 4 \mathrm{~m}$ thick fims by ten successive dip/pyrolysis cycles. "Our experience shows that applying films of varying thicknesses by a single spin coating or several spin coats as needed produces significantly greater fim uniformity and continuity compared whth the dip process, although the katter is equally usable with our materials. The reported films have a $T_{c}$ (onser) $=90 \mathrm{~K}$ yet reach $R=0$ at $60 \mathrm{~K}$ with a tail that suggests impurities or inhomogeneities.

Another interesting fim preparation technique employs sol-gel precursors. ${ }^{13}$ The electrical characteristics of these fims are extremely good; however, the sol-gel process requires slow heating with times on the order of $48 \mathrm{~h}$ to drive off solvent.

We have demonstrated a versatile new technique for preparation of high-temperature cuprate superconductors. Metalorganic solutions are used to deposit flms by spin coating, dipping, brushing, or spraying. The electrical char- acteristics of our films are better than those reported for other solution application techniques and the spin coating one process offers the greatest versatility. Exrremely short processing times of three minutes at $990^{\circ} \mathrm{C}$ give highly oriented superconducting fims with the $c$ axis perpendicular to the fIm plane. Processing at lower temperatures for similar times produces more randomly oriented fims. This preliminary report represents the beginning of more extensive studies into the variety of applications of our metalorganic process. Many experiments are in progress to decrease the width of the superconducting transition, the morphology of the fims, and the applications of the metalorganic precursors.

Note added in proof. We have found that films of less than fm do not exhibit the cracking seen in the thicker films. Films prepared by wo successive coatings of 0.5 am formed by pyrolysis at $990^{\circ} \mathrm{C}$ show improved $J_{c}=10^{4} \mathrm{~A} \mathrm{~cm}^{-2}$ at $65 \mathrm{~K}$ with $I_{C}$ similar to the above films.

We are indebted to H. M. O'Bryan for helpful discussions.

SM. K. Wu, I. R. Ashburn, C. I. Torng, P. H. Hor, R. I. Meng, R. Gio, Z. J. Huang, Y. Q. Wang, and C. W. Chu, Phys. Rev. Lett. 58, 908 (1987). R. J. Cava, B. Batlogg, R. B. van Dover, D. W. Murphys, S. Sunshine, T. Siegrist., J. P. Remeika, E. A. Reitman, S. Zahurak, and G. P. Fspinosa, Phys. Rev. Lett. 58,1676 (1987).

${ }^{3}$ See, for example, Sec. II, Processing and Fabrication, in Adv. Ceram. Mater. 2, 327-562 (1987).

${ }^{4}$ R. B. Labowitz, R. H. Koch, P. Chaudhari, and R. I. Gambino, Phys. Rev. B 35, 8821 (1987)

'M. Hong, S. H. Liou, J. Kwo, and B. Davidson, Appl. Phys. Lett. 31, 694 (1987).

'5. Kwo, T. C. Hsieh, R. M. Flening, M. Hong, S. H. Liou, B. A. Davidson, and L. C. Feldman, Prys. Rev. B 36, 4039 (1987).

7X. D. Wu, D. Dijkkamp, S. B. Ogale, A. Inam, E. W. Chase, P. F. Miceli, C.C.Chang, M. Marascon, and T. Venkatesan, Apph. Phys. Lett. 51,851 (1987).

${ }^{8}$ G. W. Vest and S. Singaram, in Defect Properties and Processing of HighTechnology Nonmetallic Materials, edited by Y. Chen. W. D. Kingery, and R. J. Stokes (North-Holland, New York, 1986), pp. 35-42.

"M. E. Gross, A. Appelbaum, and P. K. Gallagher, I. Appl. Phys. 61, 1628 (1987); P. K. Gallagher and M. E. Gross, J. Therm. Anal. 31, 1231 (1986).

"C. E. Rice. R. B. van Dover, and G. J. Fisanick (unpublished).

"T. Kunagai, H. Yokota, K. Kawaguchi, W. Kondo, and S. Mizuta, Chem. Lett. 1987, 1645 (1987).

2M. E. Gross, M. Hong, P. K. Gallagher, and S. F. Liou (unpubished).

13. Barboux, J. M. Tarascon, L. H. Greene, G. W. Hull, and B. G. Bagley (unpublished). 